\title{
SOME ASPECTS ON MAPPING TECHNOLOGIES USED FOR CAPTURING AND MODELLING OF SMALL ARCHITECTURAL OBJECTS
}

\author{
Indrius Kuklys ${ }^{1}, *$ Dainora Jankauskiené $\dot{1}^{1,2}$, Lina Kuklienè $\dot{1}^{1}$, Birutė Ruzgienè $\dot{1}^{1}$ \\ ${ }^{1}$ Klaipeda State University of Applied Sciences, Lithuania \\ ${ }^{2}$ Latvia University of Life Sciences and Technologies, Latvia \\ *Corresponding author's email: d.jankauskiene@kvk.lt
}

\begin{abstract}
The mapping of protected architectural heritage objects acquiring valuable geoinformation data is relevant today and in the future. The research is based on detection the preferable mapping technique for inspection and capturing the position of small architectural objects in public space, presenting the real geographic/ cartographic information for consumers in appropriate digital environment. The analysis and discussion involve the definition of appropriate technology, implementing goals of the culture strategy in Lithuania, preserving and updating information about cultural monuments, creating the open access to everyone.

Applying different techniques, two projects were realized: 1) the mapping and 3D modelling of sculptures in public space - small objects of city park; 2) the mapping of architectural heritage object - field museum, located in open territory with natural topography. Up-to-date mapping/ surveying methodologies as Remote Sensing (RS), Aerial Photogrammetry, Terrestrial Lidar Scanning (TLS), specialized geoinformation systems, UAV-Photogrammetry and classical surveying have been used for providing the spatial products of area topography and 3D models of any architectural objects, opening up cultural values of protected unique objects for the public and allows them to be easily accessed remotely.

The analysis of results deals with applicability of TLS technique, that provides effectiveness of 3D modelling and UAV-Photogrammetry with high resolution of aerial imaging and modelling solution. Some disadvantages have been highlighted on the use of orthophoto map for Geographic Information Systems (GIS) needs.

Key words: 3D modelling technologies, small architectural objects, terrestrial laser scanning, UAV-photogrammetry, data processing, orthophoto map.
\end{abstract}

\section{Introduction}

The mapping of protected cultural heritage objects is relevant today and in the future. The idea is to commemorate cultural heritage objects, protecting them from degradation, to ensure the preservation of information, to increase the relevance and visibility, and to realize more convenient access to obtaine GIS and geoinformation data.

Various institutions are involved with the common goal of promoting cultural heritage to Lithuanian and foreign residents by using information technologies. The digital maps are becoming public and accessible at the website to anyone who is interested.

Terrestrial Laser Scanning (TLS) refers to terrestrial Light Detection and Ranging (LiDAR) technology that captures XYZ coordinates of numerous points on surfaces by emitting laser pulses at those points and measuring the distance from the device to the target. Due to the large amount of data stored in a TLS point cloud, software packages are typically required to manage and analyze the data. A point cloud can be converted into a grid Digital Elevation Model (DEM) to facilitate topographic mapping and spatial analysis. TLS instruments are commonly divided into three categories based on the distance the laser light can travel to record a point in a field-of-view: short, medium and long-range scanners. A potential limitation to TLS approaches is the weight of the instrument ( $>20 \mathrm{~kg}$ including the battery) (Vosselman \& Maas, 2010; Terrestrial Laser Scanning, 2020).
Unmanned Aerial Vehicle (UAV) is the platform that flies at low altitude and the integrated camera can successfully capture the images of different territories/ surfaces. UAVs of different models, classification and categories can be used for aerial mapping. The methodology of UAV photogrammetry is related to image data acquisition, processing and generation of aerial image products used in cartography, surveying or GIS. UAV photogrammetry is rapidly changing the classical methods of geodesy. A UAV with a mounted camera flying at low altitude above the ground has advantages especially in capturing images of linear objects and cultural monuments. It is possible to capture images when flying over different, dangerous areas: hilly areas, tidal or volcanic areas, earthquake areas, etc. (Černiauskas \& Bručas, 2014; Haala et al., 2011; Ruzgienè, Berteška et al., 2015).

Nowadays, aerial surveying is one of the most popular methods to collect 3D information about the surface and other objects with the help of high-resolution images. The quality of the images and aerial survey products mainly depends on the successful performance of the aerial mission, the qualified management of the photogrammetric workflow, and the appropriate development of the aerial survey requirements. The UAV mission must be conducted in good meteorological conditions light wind (1.6-3.3 $\mathrm{m} \mathrm{s}^{-1}$ ) and minimal cloud cover (Ruzgienè et al., 2017; Eisenbeiss, 2009; Neitzel et al., 2011; Linder, 2009). 
The goal of research is to describe the preferable mapping technique for inspection and capturing the position of small architectural objects in public space, presenting the real geographic/ cartographic information for consumers in appropriate digital environment.

\section{Materials and Methods}

The goal of the research is to find out an effective technology for mapping, visualization and inspection of small objects of cultural/architectural heritage, such as sculptures, located in regional parks. The goal of the cultural strategy in Lithuania is to preserve and update the cultural objects that unite European cultural values, ensure their continuity, create open access and competitiveness in contemporary cultural diversity. Current mapping/surveying methods such as Remote Sensing (RS), aerial cartography with the use of UAV photogrammetry, TLS and GIS provide the spatial products of area topography and 3D models of any architectural objects, which open up cultural values of protected unique objects to the public and enable easy remote access.

The new Leica Nova MS60 MultiStation enables single-device surveying, combining high-speed 3D laser scanning capabilities, GNSS connectivity and digital imaging. Features of the MS60 include a high laser speed of up to 30,000 points per second, optimized scan area definitions, customized scan management and an improved scan path for zenith scans. Measurement professionals can make decisions and perform point cloud analysis, such as flatness analysis, directly in the field. With the Nova MS60 scan data, point positions in the field can be displayed graphically and in real time (GPS World, 2020).

Laser Scanner Stonex X300 made in Italy is a 3D scanner designed to deliver effective results every day and on every project. X300 has its own line of accessories to work better, it can control smartphone or tablet, allows it to work where others fail, regardless of dust, humidity, heat or shocks (Stonex, 2020).

3Dreshaper is a scanner software for surveyors and can perform point cloud processing (manual and automatic filters, merging, colour), 3D meshes (smoothing, filling holes, enhancing edges), 3D inspection of data, polylines, CAD surfaces, calculating Digital Surface Model, longitudinal profiles, classifying points, etc. JRC 3D Reconstructor is the cross-platform, powerful software to manage LiDAR point clouds: import, process and manage data from terrestrial, handheld, mobile and airborne laser scanners and easily integrate UAV and 3D image data in a single platform (Reshapter 3D; JRC 3D Reconstructor, 2020).

The use of Unmanned Aerial Vehicle (UAV) with integrated technical means (cameras, laser scanners,
GPNS) for mapping various objects leads to a new standard of surveying technology. The standard technical means of Dà-Jiāng Innovations (DJI), China, used for surface mapping: the unmanned aerial vehicle MATRICE 600 PRO with the possibility of integrating the Zenmuse X5 camera, the ZENMUSE XT thermal camera, the MAPPER LITE 2 laser scanner, GPNS, etc. The MATRICE 600 PRO can work all day long and work efficiently for those who require the product of high accuracy. The integrated UAV camera is equipped with an image sensor that captures very sharp and colorful images. For UAV launching, the risk elements should be clarified, such as obstacles, wind speed (Dji Enterprise, 2020).

Pix4Dmapper, an image processing software developed in Switzerland, is the main tool for applying advanced technologies in UAV deployment. The software comes with computer vision algorithms combined with photogrammetric techniques to produce products with the highest accuracy and with minimal manual interaction. Pix4Dmapper software provides efficient capabilities for generating orthophotos, surface modelling, etc. Workflows with this package are fully automated and flexible, data input is scalable, output data is easily editable and on-site quality assessment is instantaneous (Pix4D, 2020).

By using different technologies, platforms and sensors to collect point data and images, the main processing procedures remain as follows: Aerial triangulation, image orientation, point cloud generation for surface modelling, orthophoto map generation, and vector data acquisition for GIS or cartographic needs. The relationship between images and object coordinates can be established when the coordinates of ground control points are determined using classical surveying technologies that measure with global positioning systems (GPS) or total stations (McGlone, 2004; Rock et al., 2011; Nurminen et al., 2013).

In order to describe some aspects of mapping technologies getting the real time information about sculptures and topography, defining the best solution for selection of appropriate mapping technique, the GIS and photogrammetric workflow was developed as follows:

- Realization of two projects:

1. The mapping of sculptures in public space small objects of the city park;

2. The mapping of architectural heritage object the field museum, located in open not densely dwelled territory with natural topography.

- First project:

- Scanning of sculptures by the use of terrestrial laser scanner (TLS technology) and taking photography by the camera;

- 3D modelling of sculptures surfaces by the special software - 3D Reshaper; 
- Construction of the thematic map using GIS techniques (ArcGIS) - overlaying positions of sculptures on the orthophoto map and showing the routs for public needs.

- Second project:

- UAV flight to capture images with the high resolution camera.

- Simultaneous scanning of the surface using LiDAR during the UAV flight.

- Image data processing: generation of point cloud, 3D model and orthophoto.

- Surface modelling from LiDAR data.

- Analysis and evaluation of the results of the project realisation.

\section{Results and Discussion}

During experimental investigations two projects have been realized with different objectives (technologies), area features, objects and topography: 1) mapping of sculptures - small objects located in thecity park/ public space; 2) mapping of architectural heritage object - the field museum, located in open territory with natural topography.

First project. Study area - the sculptures park located in Klaipeda city, Lithuania is the open-air art gallery with 116 works of art of various thematic and 6 historical objects, situated on an area of 10 ha (Figure 1). This object was selected because of great signifficance as nature and art monument combining historical memorial legacy, modern decorative sculptures and the use of public space for cultural events. The mapping of sculpture park objects is important activity for obtaining information that can be used for construction a modern data base, disseminating for everyone's needs by the use of smart devices (Mažosios Lietuvos, 2020).

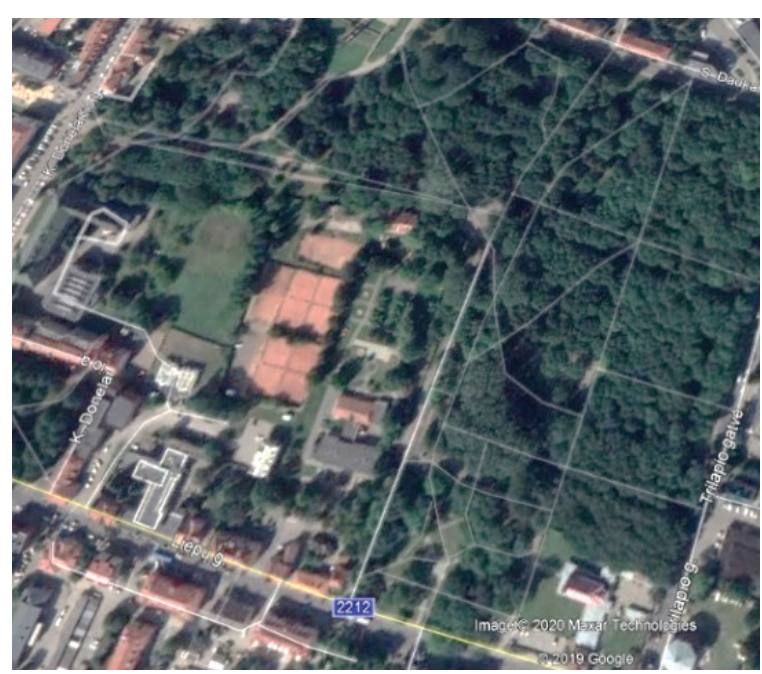

Figure 1. Study area: general view and fragment of sculptures park in Klaipeda city from Google Earth application.
Data acquisition and processing. 116 sculptures and 6 historical objects were scanned by the use of TLS with laser scanner Leica Nova MS60.

The photographs of all sculptures by the use of high-resolution camera were gained from four stations (at the sides, front, rear of the sculpture) and sometimes from additional stations depending on the complexity of the sculpture. These photographs were used for 3D modelling.

Software 3D Reshaper has been applied for 3D modelling of all sculptures in a virtual environment. The virtual geoinformation data can be found at the platforms of www.regia.lt or www.mlim.lt and can be used by everyone. 3D modelling was performed step by step: importation of points cloud gained from laser scanning of sculptures; TIN creation, filling of gaps; creating of real image; shading of invisible areas, generation of three-dimension model.

The example of 3D modelled sculpture named "Bangpūtys" by software $3 D$ Reshaper is presented in Figures 2, 3 and 4.
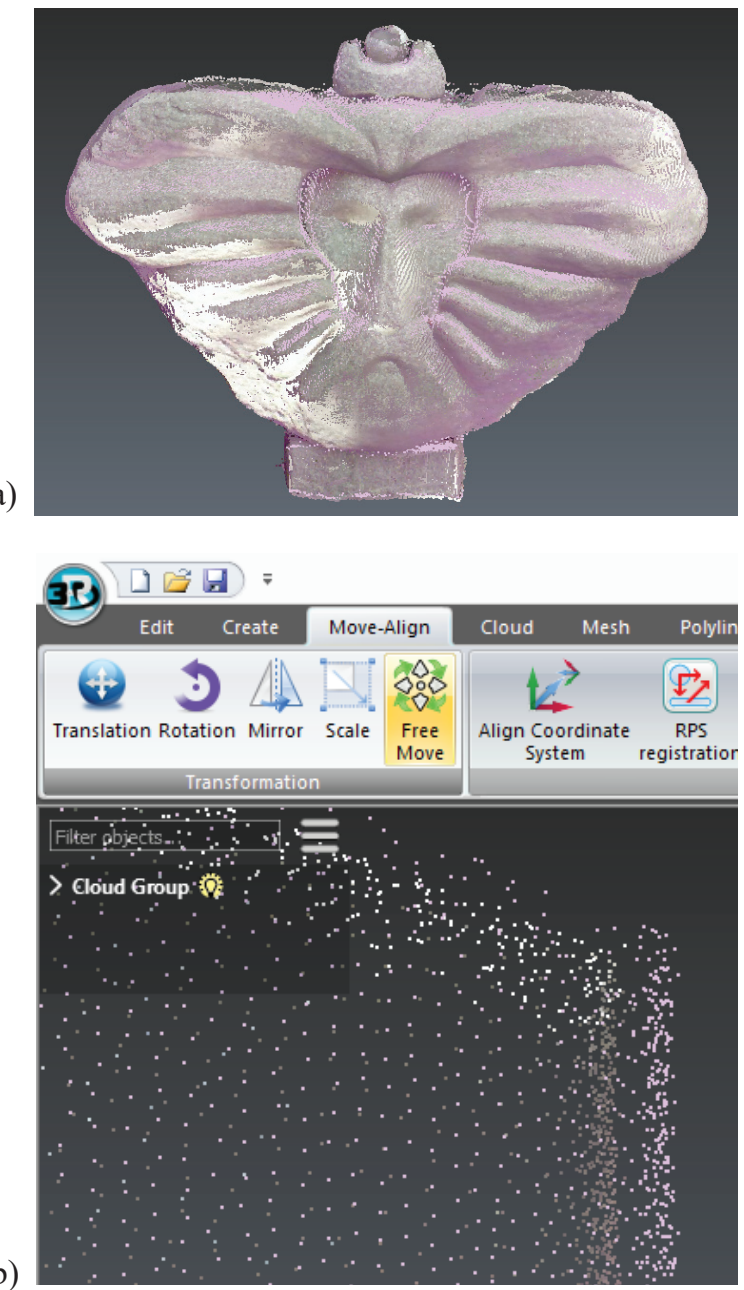

Figure 2. a) View of sculpture named "Bangpūtys" b) Point cloud imported in $3 D$ Reshaper software. 


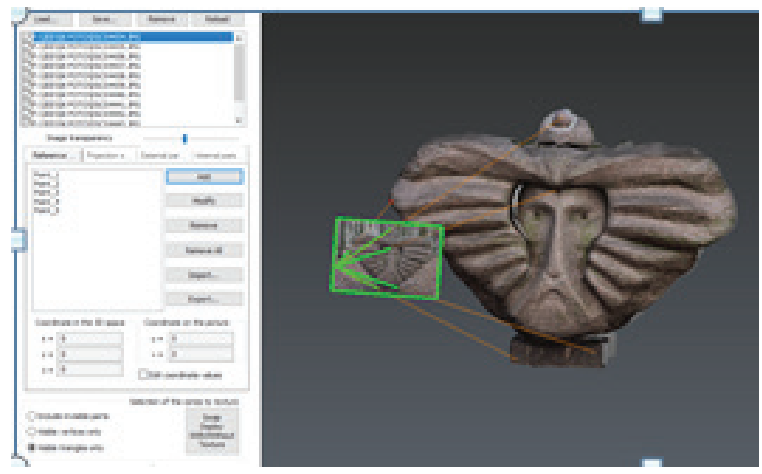

Figure 3. Extraction of a real image model: orientation of sculpture model, used 4 photographs.

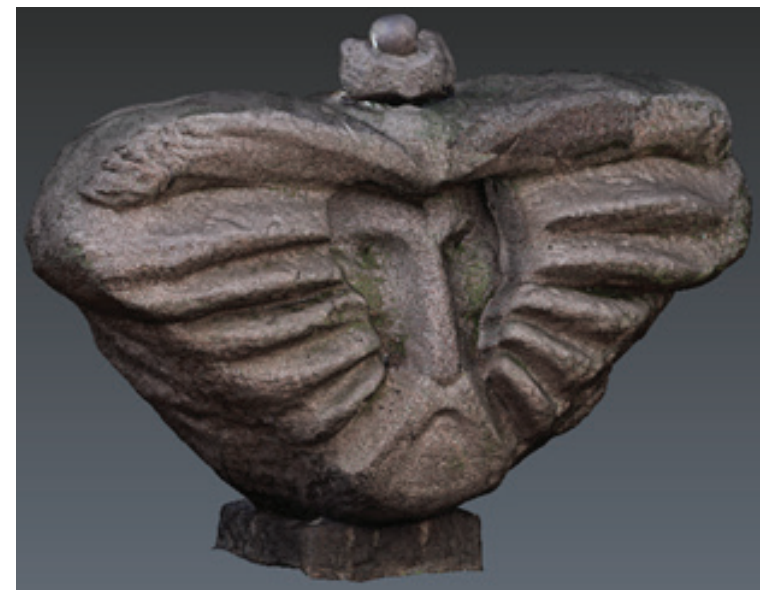

Figure 4. 3D model of sculpture „Bangpūtys“ generated from TLS data.

Thematic map construction. The spatial data set was created with software application ArcGIS. The orthophoto map of study area and topographic survey with sculptures planimetric coordinates were provided by Klaipeda city municipality. These data were imported in ArcGIS overlaying positions of sculptures onto the orthophoto map (Figure 5).

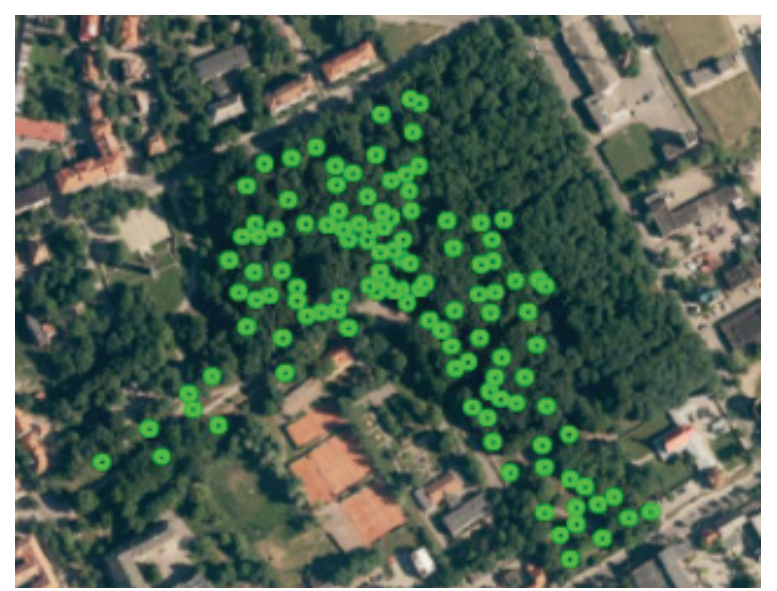

Figure 5. Sculptures position onto orthophoto map.
Figure 6 shows the constructed map of sculpture park with small objects and the routs for public needs.

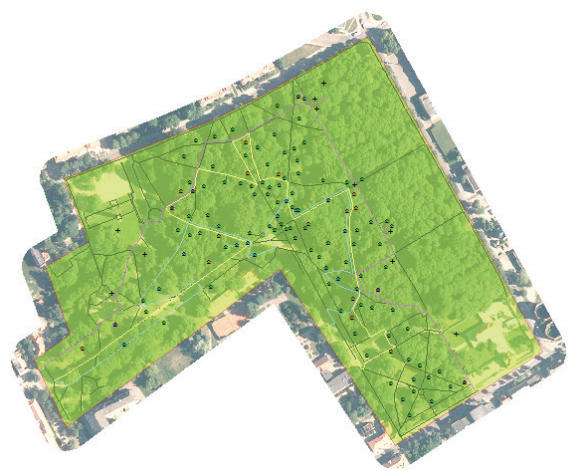

Figure 6. The map of sculpture park constructed with

GIS technology: software application ArcGIS.

Second project. Study area - architectural heritage objects Baubliai, located in Dionizo Poskos antiquities field museum, Bijotu village, Lithuania (Figure 7). Oaks that were about a thousand years old, are called Baubliai. The museum shed oak stalk with straw roof, coated by ribbons, cementitious foundations - thewriter and historian, enlightener of culture D. Poška rested and worked at the end of XIX century. Baubliai, has been declared as a significant historical, cultural, ancient monument of Lithuanian culture with no analogue. Nowadays Baubliai (Baubles) are proofed by glass covers (Baubli museum, 2020).
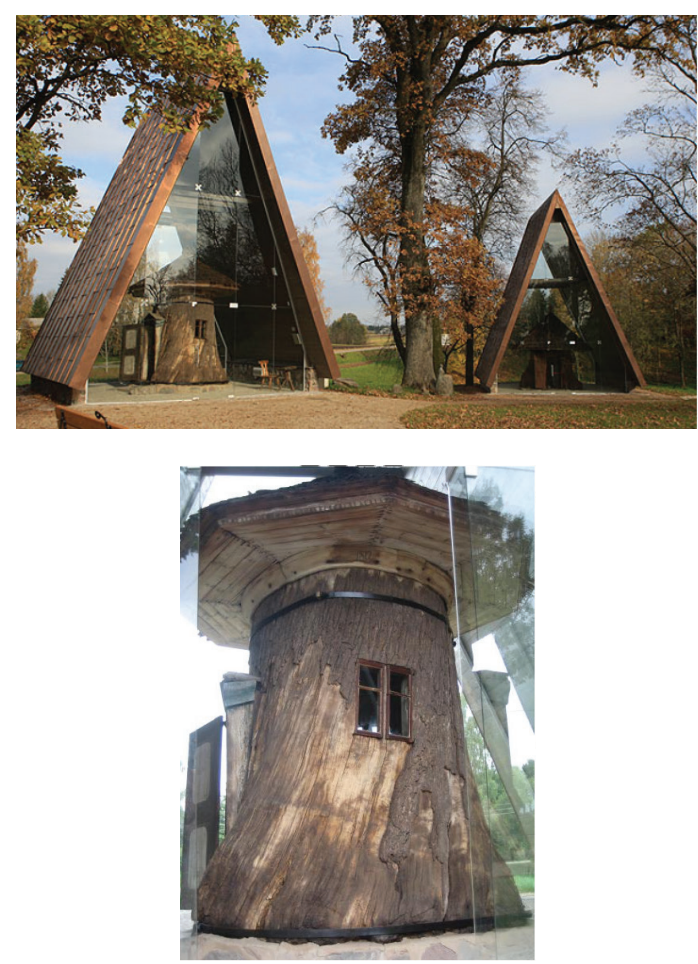

Figure7. Study area: the locality of field museum with cultural monuments Baubliai, Bijotu village. 


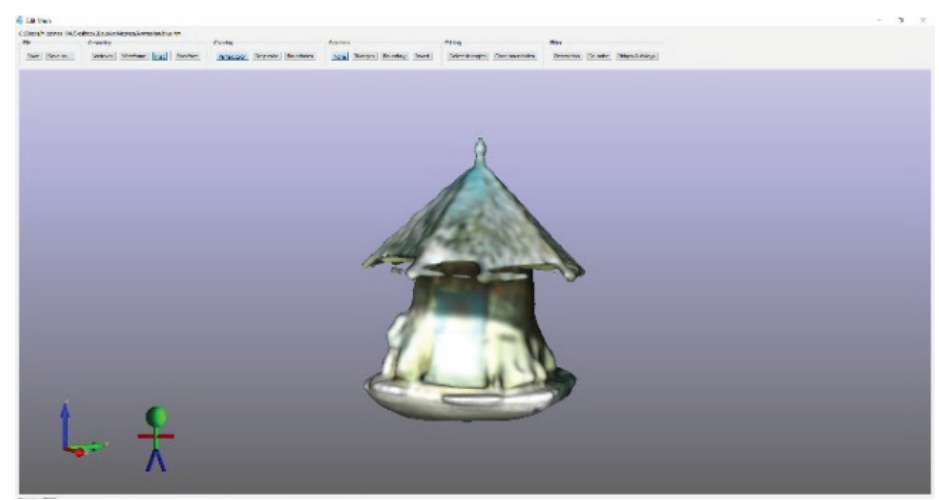

Figure 8. Generated 3D model by the use of TLS technology.

Figure 9. UAV flight routes executed over territory of museum: mission hub - Litchi for DJI Mavic, version 2.9.1.

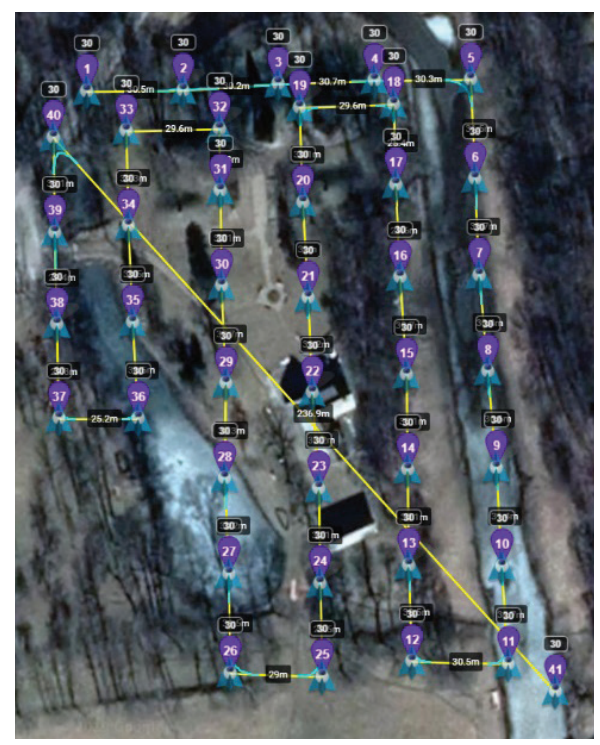

Measurements and mapping procedures. Two Baubles were scanned with laser scanner Stonex X300 - used TLS technology. Because both Baubles were under a closed glass and enclosure with a roof, the scanning procedure becomes complicated. For both Baubles, due to the trapezoidal roof, it was decided to measure from six different positions outside and also inside with scanning angle 75-90 angles. Measuring conditions were made more difficult because of the tapering roof; therefore, the laser scanner had to be raised higher. Due to the difficult measurement conditions mentioned above, the measurements took five hours. 3D modelling of Baubles was performed with software JRC 3D Reconstructor processing, unifying, correcting of the point cloud. Generated 3D model of one Bauble is presented in Figure 8.

UAV photogrammetry technology was used for experimental measurements. The low-cost and lightweight drone, model MATRICE 600 PRO, DJI with mounted gimbal camera Zenmuse X5 (sensor size $-17.3 \times 13.0 \mathrm{~mm}$, resolution $-4608 \times 3456 \mathrm{px}$., focal length $-15 \mathrm{~mm}$ ) was used for photogrammetric data acquisition. Before taking the images, a photogrammetric network was created -8 ground control points $(\mathrm{GCPs})$ were well distributed and marked on the terrain. The coordinates of the targets were determined by GPS in the LKS94 coordinate system using the LitPOS network. The planning of the UAV flight over the experimental area was performed using Litchi hub software. Figure 9 shows the flight routes over the Baubles Museum area. The flight lasted about 20 minutes.

Digital photogrammetric software Pix4Dmapper was used for images processing, exterior orientation, generation an orthophoto map and 3D models (Figure 10). Data set consists of 396 images, georeferencing of images was obtained with accuracy of mean RMS error $-1.0 \mathrm{~cm}$.
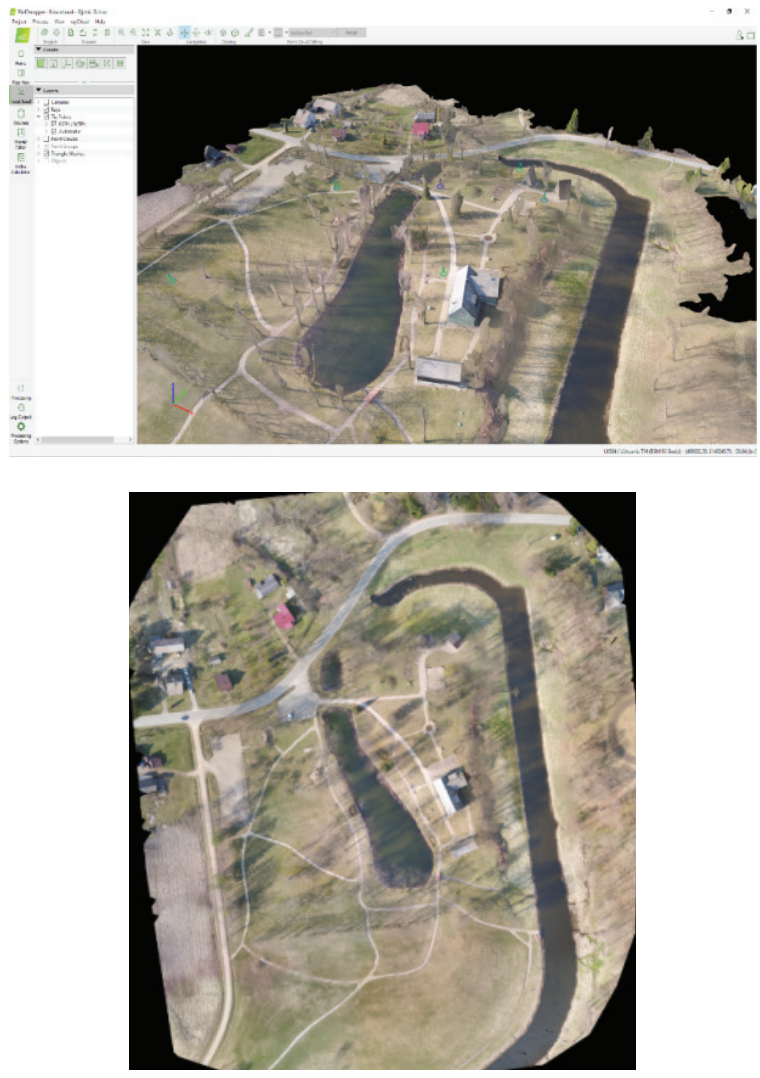

Figure 10. Aerial mapping products of museum territory: orthophoto map and DSM.

Verified survey information and survey area results include the application of various technologies to map, visualize, and inspect small cultural/ architectural heritage properties. The analysis and 
discussion involve the definition of appropriate technology, implementing goals of the culture strategy in Lithuania, preserving and updating information about cultural monuments, creating the open access to everyone.

Main features of study areas and objects are: for the first project - sculptures, located in the city park, in public space with natural topography; for the next project - field museum, two heritage objects Baubles, located in open territory.

In the first project - 3D modeling of architectural small objects and opening the way for public remote accessibility using the created map - have been used up-to-date mapping/ geoinformation technologies as follows:

- $\mathrm{RS}$ - the use imagery from satellites in Google Earth (simultaneously Street View) application for overview general situation of study object (Figure 1).

- TLS - scanning sculptures with the Leica Nova MS60 MultiStation laser scanner, 3D modeling through the use of 3D Reshaper software. The MS60 speeds up workflows by combining technologies (imaging, scanning capabilities and GNSS connectivity) in this all-in-one device. With the 3D Reshaper software, all measurement and scan data can be visualized in a $3 \mathrm{D}$ environment to perform quality and completeness corrections. The results of the applied TLS technology are shown in Figures 2, 3 and 4 (from a sculpture).

- Geoinformation Systems - the use of software application ArcGIS for thematic map construction, getting the topographic survey and coordinates from other data sources - city municipality.

- Aerial Photogrammetry - the use of orthophoto map with resolution of $10 \mathrm{~cm}$ for presentation of sculptures positions and routs in the city park for public needs (Figure 6).

In the second project - 3D modelling and mapping of open territory with the field museum and Baubles have been used such technologies:

- $\quad$ TLS - scanning Baubles with laser scanner Stonex X300, 3D modelling with software Stonex Reconstructor. Advanced scanner Stonex X300 allows quickly to collect multiple scans, software Reconstructor is powerful for 3D laser scanner data processing. Figure 8 shows the generated 3D model by the use of TLS technology.

- Classical surveying - photogrammetric network creation (reference base with 8 ground control points) measuring by GPS or total stations.

- UAV photogrammetry - aerial photography with UAV system (MATRICE 600 PRO, camera Zenmuse $\mathrm{X} 5$ ), photogrammetric data processing using Pix4Dmapper software. The results of image processing are: average Ground Sampling Distance (GSD) - $2 \mathrm{~cm}$, dataset with 396 images, camera optimization - $3.2 \%$ relative differences between initial camera parameters (below 5\%, ), matching points per image -22065 , georeferencing accuracy the average RMS error of 8 GCPs (3D) measurement is $0.010 \mathrm{~m}$ (is below $3 \times \mathrm{GSD}$ ), the overlap of images are: forward $-85 \%$ and lateral $-70 \%$. Aerial image products of the museum site: Orthophoto map and DSM (Digital Situation (or Surface) model) (Figure 4). The following rule (criteria) can be applied for accuracy assessment of aerial image products: Errors of planimetric coordinates should be higher than $1.6 \times \mathrm{GSD}$; heights $-2.5 \times \mathrm{GSD}$.

\section{Conclusions}

Research is based on defining the expedience of application of different technologies for mapping of small cultural heritage objects and their environment with different topography.

The technology of TLS was employed in two projects, using different types of laser scanners and software for 3D modelling. Comparing actions of laser scanners Leica Nova MS60 and Stonex X300 at the experimental site: these instruments were the best available solution for 3D scanning, balancing efficiency and accurate outputs, showing the scan data at the same day when it is collected. In the case when a scanned object is closed under the glass and enclosure with a roof (Baubles in the field museum), the scanning procedures became unusual (discovering station position and scanning angle). 3D laser scanner data processing with software Stonex Reconstructor is appreciated, effective and flexible.

The technology of UAV photogrammetry (MATRICE 600 PRO, Zenmuse X5, Pix4Dmapper) used in the experiment shows that such a solution for aerial photography and $3 \mathrm{D}$ modelling is successfully applicable guaranteeing high visuality of the results.

The technology of Aerial Photogrammetry is not applicable for GIS data presentation (positions of sculptures and routs for public needs) onto orthophoto map. The experimental site (the city park) is densely covered with vegetation (trees, etc.); therefore, the surface is not seen on the orthophoto map (see Figures $5,6)$. Due to different data sets accuracy, the two data bases - the orthophoto map and topographic survey are not possible to superimpose. In this case, constructing a digital map with the help of the GIS technologies, the use of aerial mapping products from UAV-Photogrammetry technology is highly recommended. 


\section{References}

Baubli museum. Retrieved March 5, 2020, from https://www.itinari.com/location/baubli-muziejus.

Dji Enterprise. How LiDAR is Revolutionizing Mapping and Geospatial Data Retrieved January 2, 2020, from https://enterprise.dji.com/news/detail/how-lidar-is-revolutionizing-mapping-and-geospatial-data.

Černiauskas, E., \& Bručas, D. (2014). A study of the use of multi-screw helicopters for monitoring tasks (in Lithuanian Daugiasraigčiu sraigtaspaniu naudojimo stebèjimo užduotims atlikti tyrimas). Vilnius: Aviacijos technologijos. 2(1): 53-58.

Eisenbeiss, H. (2009). UAV photogrammetry: Dissertation, Federal Institute of Technology (ETH), Institute of Geodesy and Photogrammetry, Zurich, Switzerland, Mitteilungen. 235 p.

GPS World. Retrieved March 3, 2020, from https://www.gpsworld.com/new-leica-nova-ms60-enablessurveying-with-one-instrument/.

Haala, N., Cramer, M., Weimer, F., \& Trittler, M. (2011). Performance Test on UAV-Based Photogrammetric Data Collection. International Archives of the Photogrammetry, Remote Sensing and Spatial Information Sciences. 38-1/C22: 7-12. DOI: 10.5194/isprsarchives-XXXVIII-1-C22-7-2011.

JRC 3D Reconstructor. Retrieved March 25, 2020, from https://www.geo3d.hr/software/gexcel/jrc-3dreconstructorr).

Kraus, K. (2007). Photogrammetry: Geometry from Images and Laser Scans. Berlin: Walter de Gruyter. 459 p.

Linder, W. (2009). Digital Photogrammetry. A practical Course. Springer-Verlag, Berlin, Heidelberg. 33-73, pp. 121-131.

Manual of Photogrammetry. (2004). In Editors by J. Chris McGlone. American Society for Photogrammetry and Remote Sensing, Maryland, USA. pp. 959-963.

The History Museum of Lithuania Minor (in Lithuania Mažosios Lietuvos istorinis muziejus). Retrieved March 2, 2020, from http://www.mlimuziejus.lt/lt/ekspozicijos/skulpturu-parkas/klaipedos-m-skulpturu-parkoistorija/skulpturu-parko-istorija/. (in Lithuanian).

Neitzel, F., \& Klonowski, J. (2011). Mobile Mapping with Low-Cost UAV System. International Archives of the Photogrammetry, Remote Sensing and Spatial Information Sciences 38-1/C22: 1-6.

Nurminen, K., Karjalainen, M., Yu, X., Hyyppä, J., \& Honkavaara, E. (2013). Performance of dense digital surface models based on image matching in the estimation of plot-level forest variables. ISPRS Journal of photogrammetry and Remote Sensing, Vol. 83, pp. 104-115.

Pi4D. Retrieved January 2, 2020, from http://pix4d.com/.

Reshapter 3D. Retrieved March 2, 2020, from https://www.3dreshaper.com/en/software-en/download-software/ current-release-software.

Rock, G., Ries, J.B., \& Udelhoven, T. (2011). Sensitivity Analysis of UAV-Photogrammetry for Creating Digital Elevation Models (DEM). International Archives of the Photogrammetry, Remote Sensing and Spatial Information Sciences 38-1/C22: 1-5.

Ruzgienė, B., Berteška, T., Gečyte, S., Jakubauskienė, E., \& Aksamitauskas, V.Č. (2015). The surface modelling based on UAV Photogrammetry and qualitative estimation. Measurement. Oxford: Elsevier Ltd. Vol. 73, pp. 619-627.

Ruzgienė, B., Aksamitauskas, V.Č., Daugèla, I., Prokopimas, Š., Puodžiukas, V., \& Rekus, D. (2015). UAV photogrammetry for road surface modelling. The Baltic journal of road and bridge engineering. Vilnius: Technika. ISSN 1822-427X. Vol. 10, No. 2, pp. 151-158.

Ruzgienė, B., Kuklienė, L., Jankauskienė, D., Kuklys, I., \& Vrubliauskienė, R. (2017). Fotogrametriniai reikalavimai, keliami aerokartografavimui: UAV-Fotogrametrija. Inžinerinès ir edukacinès technologijos (Engineering and educational technologies). Kauno technikos kolegija. ISSN 2029-9303. Nr. 2, pp. 21-28. (in Lithuanian).

Stonex. Retrieved March 15, 2020, from https://www.stonex.it/project/x300-laser-scanner/.

Terrestrial Laser Scanning. Retrieved January 20, 2020, from https://www.sciencedirect.com/topics/earth-andplanetary-sciences/terrestrial-laser-scanning.

Vosselman, G., \& Maas H.G. (2010). Airborne and terrestrial laser scanning. Boca Raton: CRC Press. 318 p. 